\title{
CFD Analysis of Temperature Variation in Semi- Circular Fins Under Forced Convection
}

\author{
Roma Singh $^{1}$,Umang Singh ${ }^{2}$ \\ ${ }^{1,2}$ Gautam Buddha University, School of Engineering, Greater Noida, India
}

\begin{abstract}
The present work gives the importance of the temperature variation in semi-circular fins under forced convection. The study includes the effect of number of semi-circular fins circumscribing the pipe on the temperature variation. The comparison has been made with the circular and the number of semi-circular fins circumscribing the pipe on the temperature variation. Fluid flowing over the fins has been consider as the forced convection and the tube side fluid has been taken as hot water flowing at constant temperature. CFD analysis has been carried out using the $2 D$ domain on Ansys Fluent 14.5 software.
\end{abstract}

Keywords: Ansys, Circular Fins, CFD, Forced Convection, Semi-Circular Fins.

\section{Introduction}

Fins are the extruded surfaces and intentionally used in common practice to enhance the heat transfer rate. The purpose of using fins are generally increase the surface area, as area exposure will be increased and hence this lead to the increment in the heat transfer rate. Essentially it is kept where the value of convective heat transfer coefficient deprived. The industrial application has been using this techniques for the enhancement of heat transfer. The waste heat recovery system consist the heat exchangers with the fins arrangements. There are numerous fins shape and size available but the selection of fin shape must be give high fin effectiveness with less manufacturing investment.

The present work emphasis on the temperature variation within the fins. The temperature difference between the tip of the fin and the base temperature must be maintain as low as possible. The low the difference the much will be higher fin effectiveness value.

CFD analysis has been carried out to evaluate the temperature variation within the fins under the steady state 2D condition. The circular fins and the number of semicircular fins will be analysed under the steady state conditions.

\section{Computational Fluid Dynamics}

CFD has been always selected for the evaluation of results of fluid flow and heat transfer beside the mathematical and numerical approach. CFD provides the easy user interface to execute the result. CFD includes all the principle of fluid flow and heat transfer.

It basically converts all the partial differential equation into algebraic one. It divides the domain into number of cells and nodes and hence calculating each nodes. It divides the problem into three steps and solve it step by step.
a. A pre-processor
b. A solver
c. A post-processor

CFD includes the following three equation for solving the problem.

\subsection{Continuity Equation}

It state that the mass can neither be created nor be destroyed. The conservation of mass principle can be written in the form of mathematical expression.

$$
\frac{\partial \rho}{\partial t}+\nabla \cdot(\rho \vec{u})=0
$$

\subsection{Momentum Equation}

This is also known as the navier strokes equation, in CFD it is define as

$$
\rho\left(u \frac{\partial u}{\partial x}+v \frac{\partial v}{\partial x}\right)=-\rho g-\frac{\partial p}{\partial x}+\mu \frac{\partial^{2} y}{\partial x^{2}}
$$

\subsection{Energy Equation}

$$
\rho c_{p}\left(u \frac{\partial T}{\partial x}+v \frac{\partial T}{\partial y}\right)=k \frac{\partial^{2} T}{\partial y^{2}}
$$

\subsection{K-epsilon Method}

The forced convection is always being associated with turbulence effect and hence the Reynold number is the function of velocity of fluid flowing. For the turbulence nature we must keep the k epsilon method on.

Where

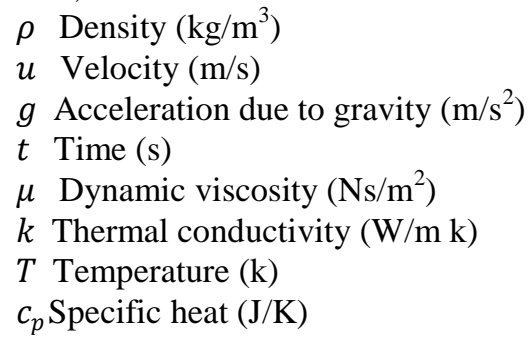

\section{Problem Setup}

The fin geometries consist of semi-circular and circular fins circumscribing the circular pipe under force convection. The diameter of circular pipe has been taken as $25 \mathrm{~mm}$, thickness has been taken as $8 \mathrm{~mm}$. The radius of semi-circular fins has 


\section{International Journal of Science and Research (IJSR) \\ ISSN (Online): 2319-7064 \\ Index Copernicus Value (2013): 6.14 | Impact Factor (2015): 6.391}

been set as $11.8 \mathrm{~mm}$ for the 4 semi-circular fins and $8.8 \mathrm{~mm}$ for the 6 semi-circular fins. The radius of circular fins has been taken as $23.4 \mathrm{~mm}$ [1]. The 2D model of semi-circular fin and circular fin will be analysed in Fluent Ansys 14.5. The geometrical modelling has been done on Catia V5.

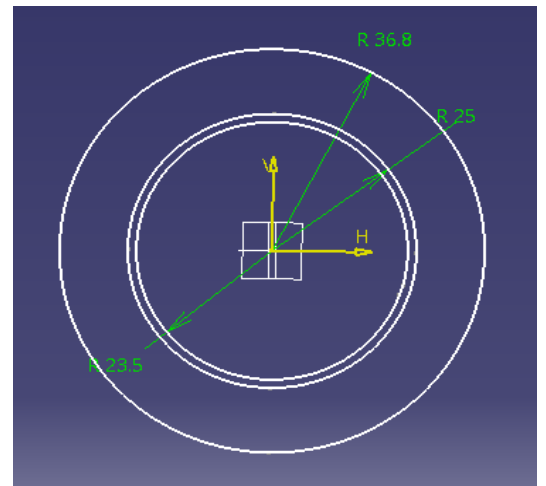

Figure 1: Circular Fin circumscribing on pipe on Catia V5
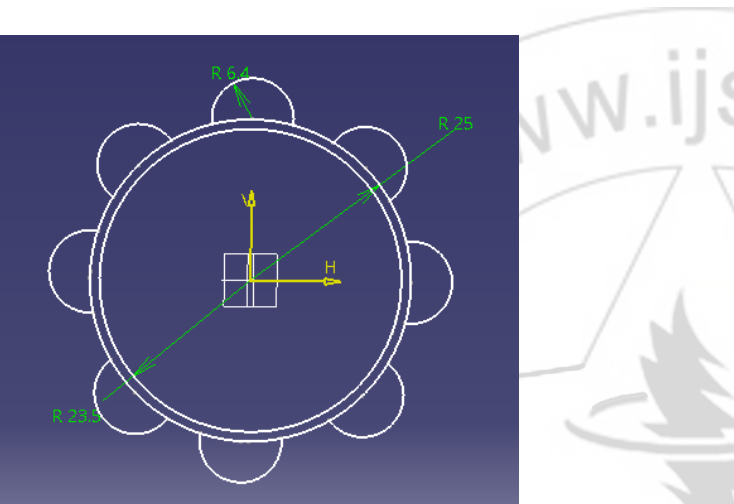

Figure 2:8 Semi-circular Fin circumscribing on pipe on Catia V5

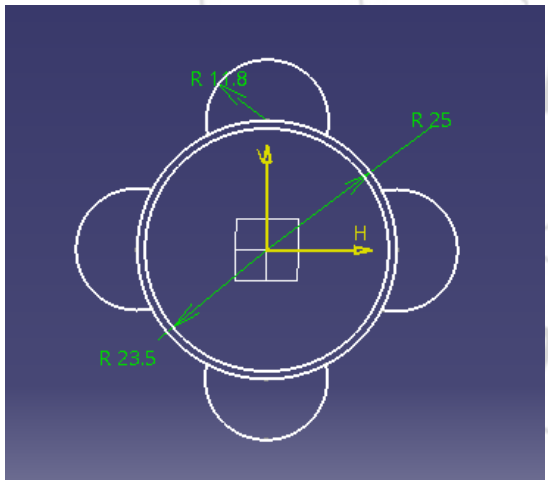

Figure 3:4 Semi-circular Fin circumscribing on pipe on Catia V5

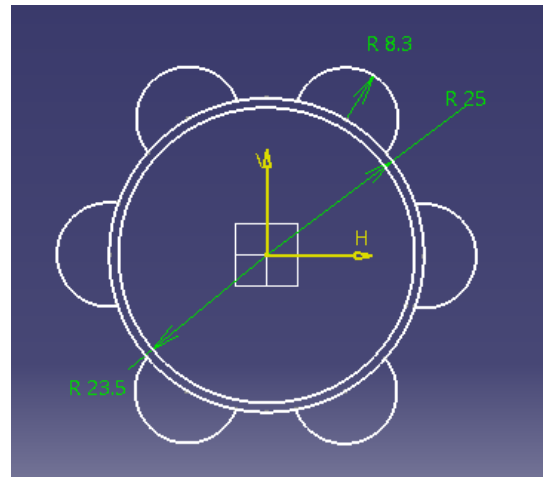

Figure 4:6 Semi-circular Fin circumscribing on pipe on Catia V5

\subsection{Modelling and Simulation}

The 2D model has been created in Catia V5. Created model has been imported to ANSYS in the file format called 'igs'. The imported model need to freeze and further simulation will be done on steady state.

\subsection{Meshing}

Mesh quality must be very fine because result is highly depend on the mesh quality. Mesh created the number of nodes around the domain or it split the domain in very precise cells. As much as small will be the distance between the nodes points, the better and concise will be result. Always select the mesh as fine and the elements shape can be selected as tetrahedral.

\subsection{Boundary Condition}

After the meshed domain, the simulation will be done on after applying the boundary conditions. Specifying the proper boundary conditions lead to the extraction of result close to the exactness. The boundary conditions includes the velocity input, temperature input, heat flux input. The boundary inputs will be given as

Table 1: Specification of Material Properties

\begin{tabular}{|c|c|c|}
\hline S. No & Properties & Value \\
\hline 1 & Material type & Aluminium \\
\hline 2 & Thermal conductivity & $90 \mathrm{~W} / \mathrm{mk}$ \\
\hline 3 & Specific heat of aluminium & $950.096 \mathrm{~J} / \mathrm{Kg} \mathrm{K}$ \\
\hline
\end{tabular}

The inlet air velocity has been taken as $1.5 \mathrm{~m} / \mathrm{s}$. The inlet temperature has been taken as $300 \mathrm{k}$ and the water flowing inside the tube having the temperature of $400 \mathrm{k}$.

\section{Result and Discussion}

The results has been obtained under steady state condition. The following are the results and graph

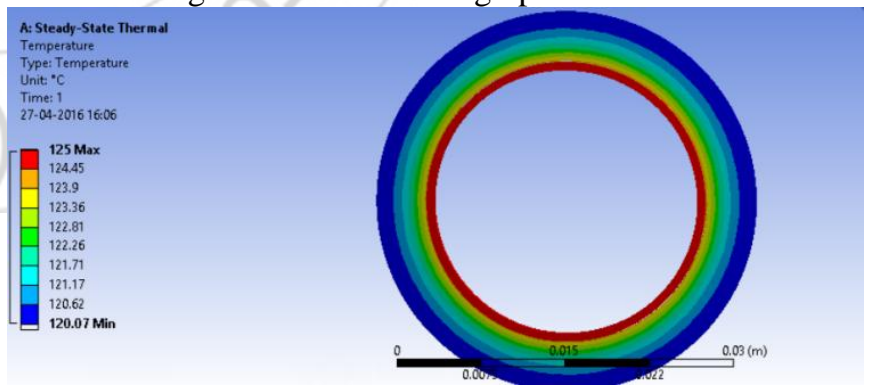

Figure 5: Temperature Variation in Circular Fin Circumscribing the Pipe

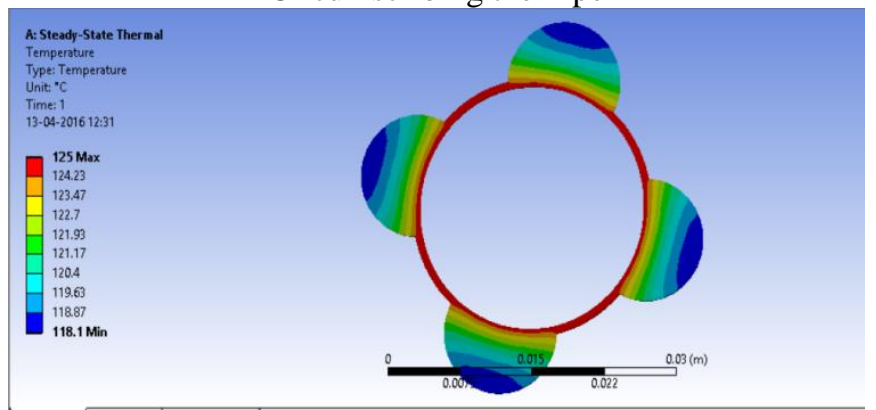

Figure 6: Temperature Variation in 4 Semi-Circular Fin Circumscribing the Pipe 


\section{International Journal of Science and Research (IJSR) \\ ISSN (Online): 2319-7064}

Index Copernicus Value (2013): 6.14 | Impact Factor (2015): 6.391

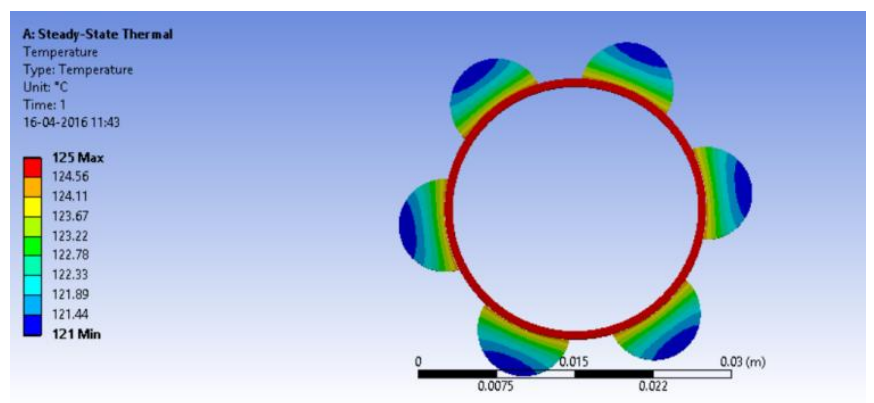

Figure 7: Temperature Variation in 6 Semi-Circular Fin Circumscribing the Pipe

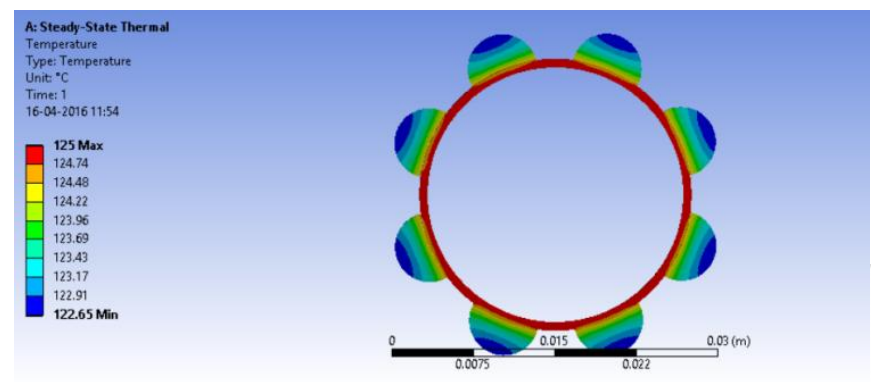

Figure 8: Temperature Variation in 8 Semi-Circular Fin

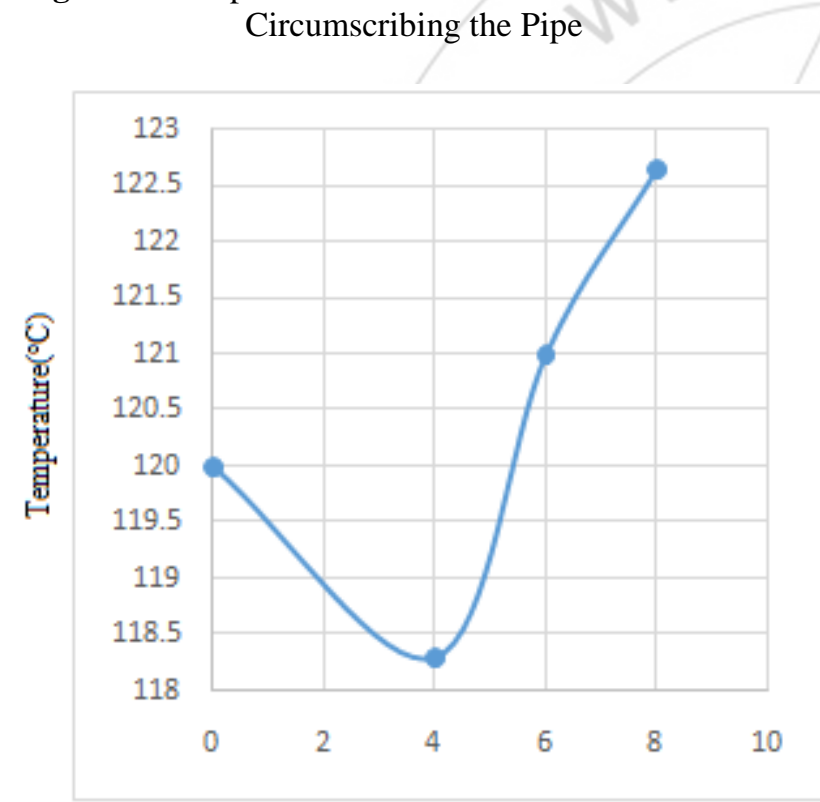

Number of Semi-circular fins

Figure 9: Comparatively study between the number of semicircular fins and circular fins

\section{Conclusion}

After summarizing all the results previously obtained, we can conclude that fin must be designed in such a way that the temperature difference between the tip of fin and base of fin must be as low as possible. If outer fin temperature affects the heat transfer from fin tip to surrounding air and hence the objective of the work favours the increment in outlet temperature of incoming air, which is subjected to convection.

The number of semi-circular fins affects the heat transfer, as the fins increases the surface area will also increase, it can be analysed by comparing the result obtained.

\section{References}

[1] R. Sengupta, R. Chakraborty, "Assessment of thermal performance of semi-circular fin under forced air convection: application to air-preheater", 4th International Conference on Advances in Energy Research, ICAER, 2013.

[2] ParinyaPongsoi, Santi Pikulkajorn, SomchaiWongwises, "Heat transfer and flow characteristics of spiral fin-and-tube heat exchangers: A review", International Journal of Heat and Mass Transfer 79, pp no 417-431, 2014.

[3] N. Nagarani, K. Mayilsamy, and A. Murugesan, "Experimental, Numerical Analysis and optimization of Elliptical Annular Fins under Free Convection", IJST, Transactions of Mechanical Engineering, Vol. 37, No. M2, pp 233-239, 2013.

[4] Incropera and Dewitt, "“Fundamental of Heat and Mass Transfer".

[5] Cengel and Boles, "Heat and Mass Transfer".

\section{Author Profile}

Roma Singh received the B.Tech + M.tech Dual degrees in Mechaniical Engineering from Gautam Buddha Uniersity in 2016.

Umang Singh pursuing the Btech+Mtech Dual degree in Mechanical Engineering from Gautam Buddha University. 